\title{
Sterol Metabolism during Germination of Conidia of Aspergillus fumigatus
}

\author{
By N. J. RUSSELL \\ Department of Biochemistry, University College, \\ P.O. Box 78, Cardiff CFI I $X L$ \\ D. KERRIDGE AND J. T. BOKOR \\ Sub-Department of Chemical Microbiology, Department of Biochemistry, \\ Tennis Court Road, Cambridge CB2 I $Q W$
}

(Received 2 February 1977; revised I April 1977)

\begin{abstract}
The sterol content of germinating conidia of the opportunistic pathogenic fungus Aspergillus fumigatus has been correlated with germination phase and sensitivity to polyene antibiotics. The sterol and sterol ester contents of walls did not change during germination. The sterol ester content of membranes and cell sap remained constant during germination, whereas the sterol content increased during the outgrowth of germ tubes. On the basis of differential extraction studies it was concluded that the loss of resistance to polyenes that occurred in the early stages of swelling of conidia during germination was not due to a movement of sterol or sterol ester out of the wall.

Radioactive-labelling experiments demonstrated that, although the amounts of conidial wall sterol and sterol ester did not change during germination, they were metabolically active. Changes in the turnover rate of wall and membrane sterol and sterol ester during germination were investigated and their relationship to a possible mechanism for the change from resistance to sensitivity to polyene antibiotics is discussed.
\end{abstract}

\section{INTRODUCTION}

Dormant conidia of the opportunistic pathogen Aspergillus fumigatus 2085 are insensitive to amphotericin B methyl ester (AME). Conidia become sensitive during the early swelling stage of germination, and this sensitivity is maintained throughout the emergence of germ tubes and outgrowth of hyphae (Russell, Kerridge \& Gale, 1975).

In vivo, polyene antibiotics exert their fungicidal action by interacting with sterolcontaining membranes of sensitive organisms (Lampen, 1966; Marty \& Finkelstein, 1975; Nozawa et al., 1974; Kitajima, Sekiya \& Nozawa, 1976). Polyene action in vivo may be more complex than studies in vitro, using model systems, suggest; the interaction of polyenes with fungi is affected by factors such as the presence of a wall and the metabolic state of the organism (Kerridge \& Russell, 1975).

The distribution and nature of the lipids in fungal spores have received little rigorous attention. The topic has been reviewed by Weber \& Hess (1974), but there is a dearth of information on sterol and sterol ester metabolism during fungal spore germination. Interest in fungal sterols has concentrated largely on their role in morphogenesis and reproduction (Hendrix, 1970; Smith \& Silverman, 1973).

In view of the role of sterols in the antifungal action of polyenes, the widespread use of these antibiotics and the fact that infection by Aspergillus fumigatus arises from the germination of conidia in the lungs of susceptible persons, we have investigated sterol 
metabolism during conidial germination. One aim of the work was to determine whether the appearance of polyene sensitivity during germination of Aspergillus fumigatus conidia was due to a redistribution or synthesis of sterol or sterol ester in conidial walls and membranes. A preliminary report of the distribution of sterol and sterol ester in conidial walls and membranes has been presented (Russell, 1975).

\section{METHODS}

Source and growth of organism. Aspergillus fumigatus strain 2085 was a clinical isolate obtained from the Mycological Reference Laboratory, London School of Hygiene and Tropical Medicine. The growth and preparation of conidia were as described previously (Russell et al., 1975).

Disruption of conidia and preparation of wall and membrane fractions. Conidia were disrupted using $0.11 \mathrm{~mm}$ diam. glass beads in a Braun homogenizer, model MSK (B. Braun, Melsungen, W. Germany) cooled with solid $\mathrm{CO}_{2}$. Conidial breakage was checked microscopically, and was generally complete (> $99 \%$ ) after $45 \mathrm{~s}$. Most conidia broke to form large wall fragments and smaller membrane vesicles and fragments. Broken conidia were decanted from the beads, and the beads were washed extensively to remove cellular material.

Conidial walls were prepared by repeatedly washing the fragmented conidia with sterile distilled water until the supernatant fluid after centrifugation at $1000 \mathrm{~g}$ for $5 \mathrm{~min}$ was free of membrane fragments. This method of preparation was checked initially by chemical analysis of the purified walls, which were shown to consist of $10.1 \%(\mathrm{w} / \mathrm{w})$ protein, $80.5 \%(\mathrm{w} / \mathrm{w})$ carbohydrate, $5.3 \%(\mathrm{w} / \mathrm{w})$ lipid and $0.81 \%(\mathrm{w} / \mathrm{w})$ nucleic acid. The remaining $3.2 \%$ dry weight probably comprised components such as melanin, which were not analysed. The wall represented $87 \%$ of the dry weight of conidia, whereas this value was $57 \%$ in mycelium grown for $24 \mathrm{~h}$. Methylene blue staining of wall preparations failed to reveal membrane contamination, and this, together with the fact that $0.25 \%(\mathrm{w} / \mathrm{v})$ sodium dodecyl sulphate released $14.2 \%$ of the wall protein but only very small amounts of lipid, was taken to indicate that the wall preparations were free of cytoplasmic and membrane components.

The water washings combined with the first supernatant contained a heterogeneous mixture of cell sap and membranes; this was termed 'membrane'. No attempt was made to purify membrane types, since pilot experiments failed to achieve a separation using density gradient centrifugation methods.

Extraction and analysis of lipids. Lipids were removed from broken conidia or conidial wall preparations by two extractions with chloroform/methanol $(2: \mathrm{r}, \mathrm{v} / \mathrm{v})$ at $70^{\circ} \mathrm{C}$ for $30 \mathrm{~min}$, and the extracts were combined. Further chloroform/methanol extracts or refluxing with organic solvents failed to remove additional sterol or sterol ester. The results for the combined extracts were reproducible, and it was believed that the two extractions removed all the free sterol and sterol ester, even though the amount of sterol in saponified extracts was variable. Bound lipid was removed from chloroform/methanol-extracted preparations by refluxing with $3 \mathrm{M}$ methanolic $\mathrm{KOH}$ for $30 \mathrm{~min}$ followed by extraction with petroleum ether (b.p. 60 to $80^{\circ} \mathrm{C}$ ). Lipids were removed from membrane fractions by partitioning against chloroform/methanol (9: I, v/v). Refluxing with methanolic $\mathrm{KOH}$ failed to remove additional sterol (ester). Non-lipid contaminants were removed from all extracts by washing with $0.85 \%(\mathrm{w} / \mathrm{v}) \mathrm{NaCl}$ (Folch, Lees \& Sloane-Stanley, 1957).

Total lipid extracts were estimated gravimetrically. Sterol and sterol ester fractions were isolated by chromatography of lipid extracts on microscope slides coated with Anasil G (Analabs, North Haven, Connecticut, U.S.A.) using petroleum ether (b.p. 60 to $80{ }^{\circ} \mathrm{C}$ )/diethyl ether/formic acid (80:20:1, by vol.) as solvent. Sterol and sterol ester spots were located by reference to authentic standards; they were then removed from the plates, eluted twice with diethyl ether ( $>90 \%$ recovery), dried under a stream of nitrogen and redissolved in $0.5 \mathrm{ml}$ hexane for estimation of $E_{281.5}$ using mini-cuvettes in a Zeiss PMQII spectrophotometer. This method measured only ergosterol and 24,28-dehydroergosterol (Breivik \& Owades, 1957), but was appropriate in the present circumstances because thin-layer chromatography and gas-liquid chromatography identified more than $99 \%$ of the extract as a single component that had the staining properties of, and co-chromatographed with, authentic ergosterol. Aspergillus fumigatus 2085 was unusual, amongst the Aspergillus strains we have studied, in having such a high relative proportion of ergosterol at all stages of growth, although in all strains ergosterol was the major sterol. This agrees with published data for Aspergillus species (Weete, 1974; Weete \& Laseter, 1974), including A. fumigatus (Goulston, Goad \& Goodwin, 1967). There was some loss of sterol and sterol ester due to the instability of ergosterol, but this was minimized by extracting and analysing as rapidly as possible in subdued light. This loss did not affect the interpretation of the data, since it did not influence the specific activities.

Radioactive-labelling experiments. Mevalonic acid was not incorporated into sterol by germinating conidia, and so sodium $\left[\mathrm{U}^{-14} \mathrm{C}\right]$ acetate was used as a sterol precursor in radioactive-labelling experiments. Stock solutions of sodium $\left[\mathrm{U}^{-14} \mathrm{C}\right]$ acetate $\left(20 \mu \mathrm{Ci} \mathrm{m}^{-1}\right)$ were made up in water and stored at $-20{ }^{\circ} \mathrm{C}$. 
Several methods of labelling conidial sterol were investigated, including the production of 'prelabelled' dormant conidia on solid media supplemented with large amounts of sodium $\left[\mathrm{U}-{ }^{14} \mathrm{C}\right]$ acetate. Although radioactive conidia could be obtained the results were inconsistent, and the low sterol and sterol ester specific activities precluded further experimentation. Steady-state labelling, combined with 'label-chase' and 'pulse-chase' experiments, was therefore employed. In 'label-chase' experiments sodium [U-14 C]acetate $\left(0.5 \mu \mathrm{Ci} \mathrm{ml}{ }^{-1}\right)$ was supplied throughout germination; at intervals samples were removed and conidia were collected by centrifugation, washed and resuspended in excess non-radioactive sodium acetate. In 'pulsechase' experiments conidia were incubated for $30 \mathrm{~min}$ in sodium [U- ${ }^{14} \mathrm{C}$ ]acetate before collection, washing and resuspension in excess non-radioactive sodium acetate. The reproducibility of such experiments was good: the data presented in Tables 3 to 7 are the mean values from two or three experiments. Sterol and sterol ester fractions were assayed in quadruplicate. After estimation of $E_{281 \cdot 5}$, radioactive samples were transferred quantitatively to scintillation vials, the solvent was evaporated, $10 \mathrm{ml}$ scintillation cocktail [containing $4 \mathrm{~g}$ 2,5-bis [5'-t-butylbenzoxazolyl(2')]thiophen per 1 toluene] was added and the samples were counted using a Packard 3375 Tri-Carb scintillation spectrophotometer. All samples quenched equally; specific activities are expressed as c.p.m. $\mu \mathrm{g}^{-1}$.

Materials. Sodium [U-14 C]acetate (specific activity $58 \mathrm{mCi} \mathrm{mmol}^{-1}$ ) was obtained from The Radiochemical Centre, Amersham. Ergosterol was purchased from Sigma; ergosteryl oleate was the generous gift of Dr T. Y. Koh. All solvents were redistilled before use and chemicals were of analytical reagent grade.

\section{RESULTS}

\section{Extraction of sterol from germinating spores}

Approximately $70 \%$ more free sterol and sterol ester could be extracted from dormant conidia after disruption (Table I). When the saponified extract sterol was included in the sterol ester fraction, the sterol/sterol ester ratio was 0.58 for dormant conidial walls and 2.I2 for membrane. There was a similar amount of chloroform/methanol-extractable sterol and sterol ester in conidia during the first $5 \mathrm{~h}$ of germination, and no change in either the proportion of residual sterol that could be extracted after saponification or the distribution of total sterol between wall and membrane (Table 2). In dormant conidia, $64.0 \%$ total sterol was found in the wall fraction and $36.0 \%$ in the membrane fraction; after $5 \mathrm{~h}$ germination, the values were 59.2 and $40.8 \%$ respectively, and after $6 \mathrm{~h}, 45.8$ and $54.2 \%$ respectively.

\section{Sterol content of conidia during germination}

The total sterol content of dormant conidia was $0.102 \pm 0.008 \%(n=14)$ dry weight. This value did not change during the initial 4 to $5 \mathrm{~h}$ germination, but it then increased to reach $0.366 \pm 0.039 \%(n=6)$ dry weight at $8 \mathrm{~h}$ (Fig. I). After $8 \mathrm{~h}$ there was outgrowth of hyphae. The sterol content of mycelium grown for $24 \mathrm{~h}$ was 0.44 to $0.47 \%$ dry weight. The increase in total sterol during the later stages of germination was due to an increase in free sterol in the membrane (Table 2). The amount of sterol and sterol ester in conidial walls was essentially constant throughout germination, whereas the sterol, but not sterol ester, content of membrane increased, leading to a large increase in the sterol/sterol ester ratio of membrane in the later stages of germination. This pattern was confirmed in many experiments in which wall and membrane fractions were prepared.

The germination of $A$. fumigatus 2085 conidia was highly synchronous, so the distinct stages of refractile (ungerminated) conidia, phase-dark conidia, swollen conidia and germ tube emergence could be obtained in bulk culture (Russell et al., 1975). Dormant conidia were resistant to more than $40 \mu \mathrm{g} \mathrm{AME} \mathrm{ml}{ }^{-1}$, but became sensitive to I to $2 \mu \mathrm{g} \mathrm{AME} \mathrm{ml}^{-1}$ after 3 to $4 \mathrm{~h}$ germination, which was the period when the phase-dark conidia began to swell (Fig. I). The increase in total sterol content, which was due to membrane sterol, occurred during the later stages of germ tube emergence (Fig. I, Table 2). 


\section{Table I. Extraction of sterol and sterol ester from germinating conidia of Aspergillus fumigatus}

Conidia (300 mg dry wt) were harvested and divided into three portions (A, B and C). A was extracted directly, B was broken and the whole extracted, and $\mathrm{C}$ was broken and fractionated into wall and membrane fractions before extraction and analysis of sterol (S) and sterol ester (SE). Results are the average of three experiments, and are expressed as $\mu \mathrm{g}$ sterol or sterol ester (100 mg dry wt conidia) $)^{-1}$.

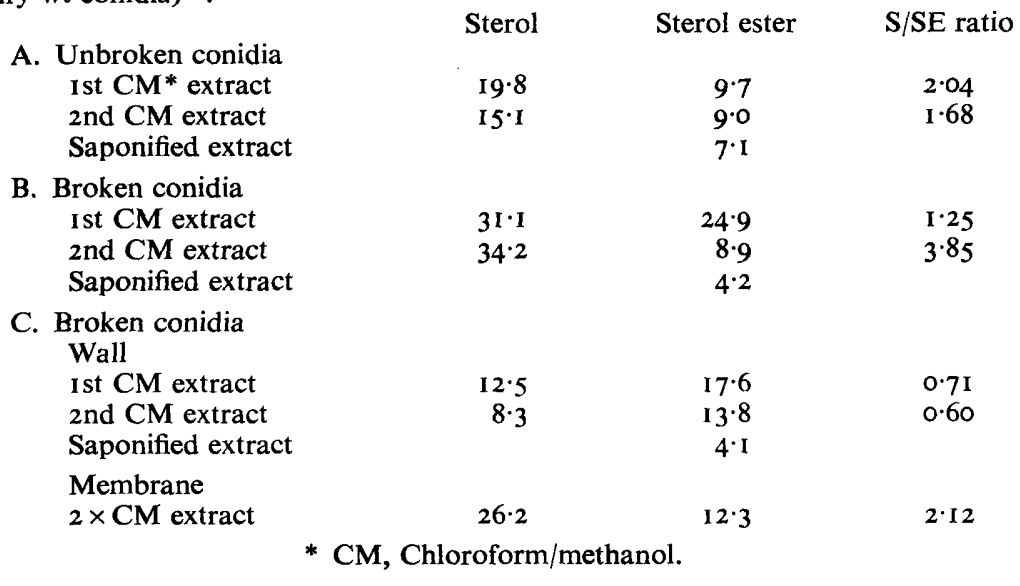

\section{Table 2. Sterol and sterol ester distribution between wall and membrane fractions in germinating conidia of Aspergillus fumigatus}

At the times indicated samples of conidia ( $100 \mathrm{mg}$ dry wt) were removed from a germination medium and collected by centrifugation; wall and membrane fractions were prepared and analysed for sterol (S) and sterol ester (SE) content. Results are the average of two experiments, and are expressed as $\mu \mathrm{g}$ sterol or sterol ester (100 $\mathrm{mg}$ dry wt conidia) ${ }^{-1}$.

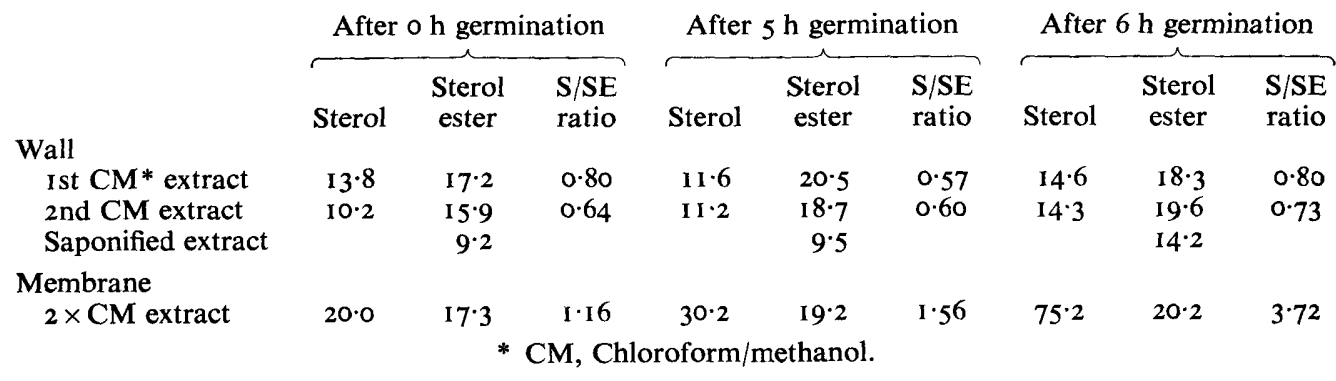

\section{Sterol metabolism during germination}

Sodium $\left[\mathrm{U}-{ }^{14} \mathrm{C}\right]$ acetate was taken up readily by conidia and incorporated into macromolecules (Fig. 2). The percentage incorporation of radioactivity from sodium $\left[{\left.\mathrm{U}-{ }^{14} \mathrm{C}\right]-}^{-}\right.$ acetate, measured over $\mathrm{I} h$ periods, increased during germination (Table 3). A high percentage of the radioactivity incorporated was recovered in the lipid fraction (Table 3 ). Between 65 and $75 \%$ of the radioactivity in the lipid fraction was in neutral lipid, and of this nearly half was in sterol and sterol ester (Table 4).

The results of labelling experiments using sodium $\left[{ }^{\mathrm{I}}-{ }^{14} \mathrm{C}\right]$ acetate are shown in Table 5 . The wall sterol and sterol ester showed little increase in specific activity after the first hour of germination, whereas the specific activity of membrane sterol and sterol ester increased during the first $6 \mathrm{~h}$ of germination.

The results of 'label-chase' experiments are shown in Table 6 . The specific activity of wall sterol and sterol ester was reduced by $34^{\circ} 0$ and $48.0 \%$ respectively by a 'chase' 


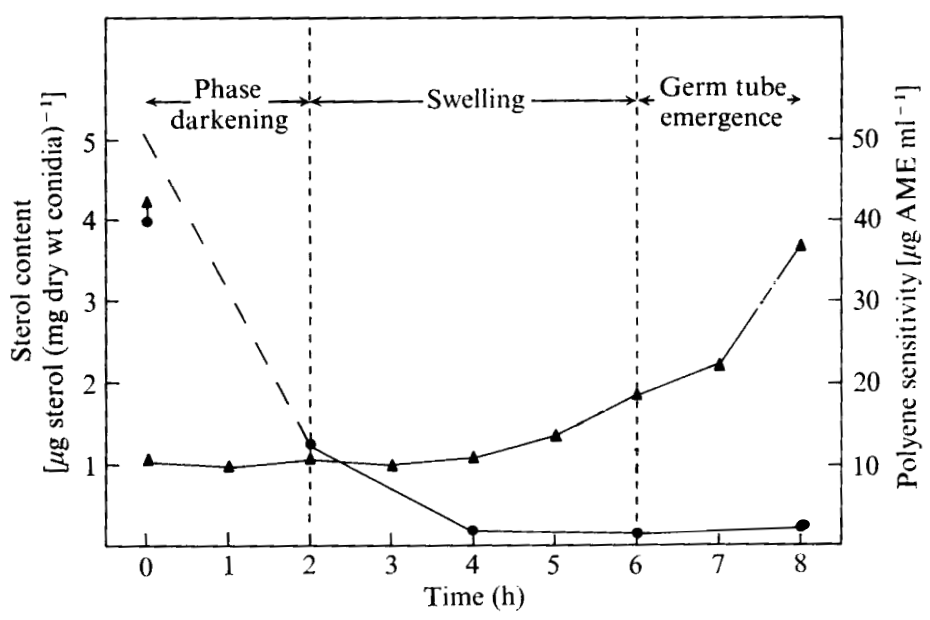

Fig. I. Correlation of total sterol content with germination phase and polyene sensitivity in Aspergillus fumigatus. Samples of conidia ( $20 \mathrm{mg}$ dry wt) were removed at intervals from the germination medium, collected by centrifugation and washed twice with sterile distilled water and disrupted. Sterol was removed by refluxing disrupted conidia in $3 \mathrm{M}$ methanolic KOH for $30 \mathrm{~min}$; the mixture was cooled, combined with an equal volume of water and extracted twice with petroleum ether (b.p. 60 to $80^{\circ} \mathrm{C}$ ). The sterol was purified by thin-layer chromatography and assayed spectrophotometrically. The germination phase and polyene sensitivity are adapted from Figs 1 and 2 in Russell et al. (1975). $\Delta$, Sterol content; $\bullet$, polyene sensitivity.

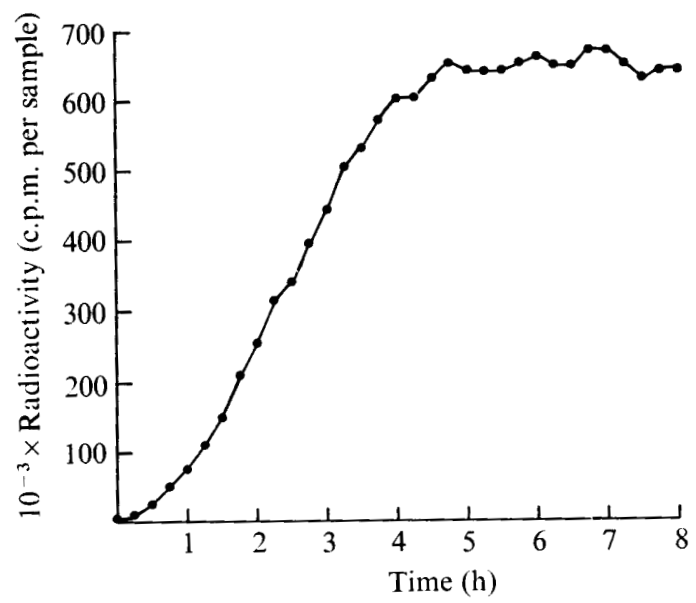

Fig. 2. Time course of sodium $\left[\mathrm{U}-{ }^{14} \mathrm{C}\right]$ acetate uptake by germinating conidia of Aspergillus fumigatus. Conidia ( $10 \mathrm{mg}$ dry $\mathrm{wt}$ ) were suspended in $50 \mathrm{ml}$ germination medium containing $25 \mu \mathrm{Ci}$ sodium [U-14 C]acetate $(4 \cdot 16 \mu \mathrm{mol})$ plus $10 \mu \mathrm{mol}$ non-radioactive sodium acetate. At $15 \mathrm{~min}$ intervals duplicate $\mathrm{r} \mathrm{ml}$ samples were removed into ice-cold $10 \%(\mathrm{w} / \mathrm{v})$ trichloroacetic acid (TCA). Samples were filtered, washed twice with $2 \mathrm{ml}$ ice-cold $5 \% \mathrm{TCA}$, once with $2 \mathrm{ml} \mathrm{I} \%(\mathrm{v} / \mathrm{v})$ acetic acid, dried and assayed by liquid scintillation spectrometry.

during the second hour of germination. A 'chase' in the fourth, fifth or seventh hours of germination reduced the specific activity of wall sterol by $I I \cdot I, 3.6$ or $0 \%$ respectively. In contrast the corresponding values for wall sterol ester were $53.8,23.1$ or $28.4 \%$. The specific activity of membrane sterol ester was reduced by $23.1,67 \cdot 3,81 \cdot 2$ or $53.2 \%$ by a 'chase' during the second, fourth, fifth or seventh hours of germination respectively. The results for membrane sterol were more complex. Membrane sterol specific activity could be reduced by $52.7 \%$ by a 'chase' during the second hour of germination, and by $20.3 \%$ 


\section{Table 3. Distribution of radioactivity in cellular components of germinating conidia of Aspergillus fumigatus}

Four samples of conidia ( $17 \mathrm{mg}$ dry wt) were dispersed in $100 \mathrm{ml}$ germination medium and incubated at $37^{\circ} \mathrm{C}$. At the times indicated $50 \mu \mathrm{Ci}$ sodium $\left[\mathrm{U}^{-14} \mathrm{C}\right.$ ]acetate $(0.8 \mu \mathrm{mol})$ plus $20 \mu \mathrm{mol}$ non-radioactive sodium acetate was added for $\mathrm{I} h$, and then the conidia were collected by centrifugation. Conidia were washed twice with sterile distilled water, disrupted and resuspended in ice-cold $5 \%$ TCA. Samples were centrifuged to give a 'pool' fraction. The pellets were extracted successively with $75 \%$ ethanol for $30 \mathrm{~min}$ at $45{ }^{\circ} \mathrm{C}$ and diethyl ether $/ 75 \%$ ethanol $(\mathrm{I}: 1, \mathrm{v} / \mathrm{v})$ for $15 \mathrm{~min}$ at $45^{\circ} \mathrm{C}$ to produce a lipid fraction. Nucleic acids were extracted by heating pellets at $95{ }^{\circ} \mathrm{C}$ for $30 \mathrm{~min}$ in $5 \%$ TCA. The residual pellet was washed with acidified diethyl ether, then diethyl ether, to leave protein plus polysaccharides, which was not fractionated further in view of the low incorporation in this fraction. After removal of TCA all samples were assayed in duplicate for radioactivity by liquid scintillation spectrometry. Results are expressed as percentages.

\begin{tabular}{|c|c|c|c|c|}
\hline & & Period & elling & \\
\hline & $0-1 \mathrm{~h}$ & $2-3 h$ & $4-5 h$ & $6-7 \mathrm{~h}$ \\
\hline Pool & $47 \cdot 2$ & $17 \cdot 9$ & $2 \cdot 8$ & 0.4 \\
\hline Lipid & $35 \cdot 5$ & $75 \cdot 3$ & $93 \cdot 9$ & $95 \cdot I$ \\
\hline Nucleic acid & $14 \cdot 6$ & $2 \cdot 2$ & $1 \cdot 4$ & $I \cdot 4$ \\
\hline Protein + polysaccharide & $2 \cdot 7$ & $4 \cdot 6$ & $I \cdot 9$ & $3 \cdot 2$ \\
\hline $\begin{array}{l}\text { Percentage utilization of } \\
\text { radioactivity }\end{array}$ & 0.5 & $I \cdot 0$ & $4 \cdot 2$ & $8 \cdot 7$ \\
\hline
\end{tabular}

\section{Table 4. Distribution of radioactivity in lipids during germination of Aspergillus fumigatus conidia}

Two samples of conidia $(25 \mathrm{mg}$ dry wt) were dispensed in $100 \mathrm{ml}$ germination medium and incubated at $37^{\circ} \mathrm{C}$. At zero time or after $3 \mathrm{~h}$ in germination medium $50 \mu \mathrm{Ci}$ sodium [U- ${ }^{14} \mathrm{C}$ ]acetate $(0.8 \mu \mathrm{mol})$ plus $20 \mu \mathrm{mol}$ non-radioactive sodium acetate was added for $\mathrm{I} \mathrm{h}$, and then the conidia were collected by centrifugation. Conidia were washed twice with sterile distilled water, disrupted and extracted twice with chloroform/methanol $(2: \mathrm{I}, \mathrm{v} / \mathrm{v})$. Lipid extracts were washed with $0.85 \% \mathrm{NaCl}$ before analysis in duplicate by thin-layer chromatography. Components were located using iodine vapour and removed for estimation of radioactivity by liquid scintillation spectrometry. Results are expressed as percentages.

\begin{tabular}{lrr} 
& \multicolumn{2}{c}{ Period of labelling } \\
Sterol ester & $1 \cdot 5$ & $3-4 \mathrm{~h}$ \\
Triglyceride & $22 \cdot 7$ & $7 \cdot 4$ \\
Free fatty acids & $8 \cdot 3$ & $25 \cdot 2$ \\
Sterol & $34 \cdot 9$ & $10 \cdot 8$ \\
Pigment & $7 \cdot 7$ & $34 \cdot \mathrm{I}$ \\
Rest of chromatogram (incl. polar lipid) & $24 \cdot 9$ & $3 \cdot 2$ \\
& & $19 \cdot 3$
\end{tabular}

during the fourth hour, whereas the specific activity was increased by $7 \cdot 6 \%$ by a 'chase' during the fifth hour; a 'chase' during the seventh hour reduced the specific activity by $\mathrm{I} \cdot 7 \%$.

Essentially the same result was obtained in 'pulse-chase' experiments (Table 7). Wall sterol and sterol ester specific activities were reduced by a 'chase' during the early and middle stages of germination. In contrast, the membrane sterol and sterol ester specific activities could be reduced by a 'chase' in the early stages, but not the middle stages of germination (Table 7). In the 'pulse-chase' experiments similar results were obtained for sterol and sterol ester, in contrast to the 'label-chase' experiments (Tables 6 and 7 ). 


\section{Table 5. Specific activities of sterol and sterol ester in germinating conidia of Aspergillus fumigatus}

Conidia ( $50 \mathrm{mg}$ dry $\mathrm{wt}$ ) were suspended in $300 \mathrm{ml}$ germination medium containing $150 \mu \mathrm{Ci}$ sodium [U- ${ }^{14} \mathrm{C}$ ]acetate $(2.5 \mu \mathrm{mol})$ plus $67 \mu \mathrm{mol}$ non-radioactive sodium acetate and incubated at $37^{\circ} \mathrm{C}$. Samples $(50 \mathrm{ml})$ were removed, and conidia were collected by centrifugation and washed twice with sterile distilled water. Conidia were disrupted, wall and membrane fractions were prepared, lipid was extracted, and sterol and sterol ester were isolated by thin-layer chromatography to determine their specific activities. Results are the average of quadruplicate assays, and are expressed as c.p.m. ( $\mu$ g sterol or sterol ester) ${ }^{-1}$.

Time of sampling

\begin{tabular}{lrrrrr} 
& \multicolumn{1}{c}{ I h } & $3 \mathrm{~h}$ & $4 \mathrm{~h}$ & $5 \mathrm{~h}$ & $6 \mathrm{~h}$ \\
Wall & & & & & \\
$\quad$ Sterol & 6312 & 10380 & 8330 & 9680 & 7140 \\
$\quad$ Sterol ester & 1960 & 1320 & 1560 & 2000 & 1820 \\
Membrane & & & & & \\
$\quad$ Sterol & $\mathrm{I} 815$ & 7890 & 32500 & 28500 & 43900 \\
$\quad$ Sterol ester & 1247 & 2535 & 8570 & 13440 & 16630
\end{tabular}

Table 6. Specific activities of sterol and sterol ester in 'label-chase' experiments in germinating conidia of Aspergillus fumigatus

Conidia ( $80 \mathrm{mg}$ dry $\mathrm{wt}$ ) were suspended in $500 \mathrm{ml}$ germination medium containing $250 \mu \mathrm{Ci}$ sodium [U- ${ }^{14} \mathrm{C}$ ]acetate $(4 \cdot 2 \mu \mathrm{mol})$ plus $100 \mu \mathrm{mol}$ non-radioactive sodium acetate and incubated at $37^{\circ} \mathrm{C}$. At the times indicated duplicate $50 \mathrm{ml}$ samples were removed, and conidia were collected by centrifugation and washed twice with sterile distilled water. One sample was disrupted for preparation of wall and membrane fractions ('label'); the other was resuspended in $50 \mathrm{ml}$ germination medium containing $50 \mu \mathrm{mol}$ non-radioactive sodium acetate and incubated for a further I $\mathrm{h}$ at $37^{\circ} \mathrm{C}$ before preparing wall and membrane fractions ('chase'). Results are the average of quadruplicate assays, and are expressed as c.p.m. ( $\mu \mathrm{g}$ sterol or sterol ester) ${ }^{-1}$.

\begin{tabular}{|c|c|c|c|c|c|c|c|c|}
\hline & \multicolumn{8}{|c|}{ Time of sampling (L) or period of chase (C) } \\
\hline & $\begin{array}{l}\text { I h } \\
\text { (L) }\end{array}$ & $\begin{array}{c}\mathrm{I}-2 \mathrm{~h} \\
\text { (C) }\end{array}$ & $\begin{array}{l}3 \mathrm{~h} \\
\text { (L) }\end{array}$ & $\begin{array}{c}3-4 h \\
\text { (C) }\end{array}$ & $\begin{array}{l}4 \mathrm{~h} \\
\text { (L) }\end{array}$ & $\begin{array}{c}4-5 h \\
\text { (C) }\end{array}$ & $\begin{array}{l}6 \mathrm{~h} \\
\text { (L) }\end{array}$ & $\begin{array}{c}6-7 \mathrm{~h} \\
\text { (C) }\end{array}$ \\
\hline \multicolumn{9}{|l|}{ Wall } \\
\hline Sterol & 3150 & 2090 & 3350 & 2980 & 3370 & 3250 & 4620 & 4630 \\
\hline Sterol ester & 1522 & 733 & 1850 & 855 & 4020 & 3090 & 3700 & 2650 \\
\hline \multicolumn{9}{|l|}{ Membrane } \\
\hline Sterol & 1230 & 582 & 7390 & 5890 & 22300 & 24000 & 29000 & 28500 \\
\hline Sterol ester & 488 & 375 & 4030 & I 313 & 6050 & 1360 & 15950 & 7470 \\
\hline
\end{tabular}

Table 7. Specific activities of sterol and sterol ester in 'pulse-chase' experiments in germinating conidia of Aspergillus fumigatus

Conidia (40 mg dry wt) were suspended in $250 \mathrm{ml}$ germination medium, divided into two equal parts and incubated at $37^{\circ} \mathrm{C}$. To the one part was added $62.5 \mu \mathrm{Ci}$ sodium [U-14 $\mathrm{C}$ ]acetate (I $\mu$ mol) plus $25 \mu \mathrm{mol}$ non-radioactive sodium acetate at zero time and to the other after $4 \mathrm{~h}$. After $30 \mathrm{~min}$ the two parts were further subdivided into two equal portions, and conidia were collected by centrifugation and washed twice with sterile distilled water. One portion was disrupted for preparation of wall and membrane fractions ('pulse'); the other was resuspended in $62.5 \mathrm{ml}$ germination medium containing $62.5 \mu \mathrm{mol}$ non-radioactive sodium acetate and incubated for a further $1.5 \mathrm{~h}$ at $37^{\circ} \mathrm{C}$ before preparing wall and membrane fractions ('chase'). Results are the average of quadruplicate assays, and are expressed as c.p.m. ( $\mu \mathrm{g}$ sterol $\mathrm{nr}$ sterol ester $)^{-1}$.

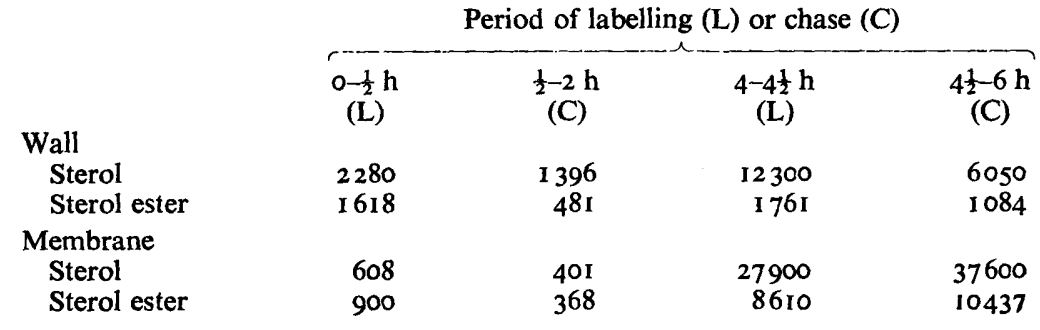




\section{DISCUSSION}

A possible mechanism for the resistance to polyene antibiotics of dormant conidia might be the combination of polyene with lipid present in the wall, thus preventing access of the antibiotic to its target site. Since, amongst lipids, sterol and sterol ester have the greatest affinity for polyenes (Gale et al., 1975), the amount and distribution of these lipids was investigated in dormant and germinating conidia. Our experiments did not support this hypothesis as there was essentially no redistribution of sterol or sterol ester between wall and membrane during germination, and the sterol and sterol ester content of conidial walls remained remarkably constant. There was no increase in conidial dry weight during the first $5 \mathrm{~h}$ of germination so the increase in total conidial sterol that occurred after $4 \mathrm{~h}$ was the result of an absolute increase in membrane sterol, whereas the membrane sterol ester remained constant. The appearance of sensitivity to polyene during germination was not related to this increase in membrane sterol since this component did not increase until well after the conidia had become sensitive. The membrane sterol increase was associated with germ tube emergence and hyphal extension and probably reflected the increase in membrane synthesis known to occur at this time.

These experiments demonstrated the necessity for breaking conidia prior to extraction to obtain complete recoveries of sterol and sterol ester. As further extractions failed to extract more sterol or sterol ester from broken conidia, the sterol in the saponified extract was probably not the result of incomplete sterol extraction by chloroform/methanol. It is possible that this sterol could be covalently linked to conidial wall polysaccharides, although there is a form of ergosterol in Saccharomyces cerevisiae which is not extracted by organic solvents and is not covalently associated with cell wall mannan (Thompson, Knights \& Parks, I973). In S. cerevisiae pyrogallol enhances sterol extraction, and there may be more than one metabolic form of such cell wall-associated sterol (Adams \& Parks, I968). It has been suggested that firmly bound lipids play a structural role in fungal walls (Nickerson, 1963).

The 'membrane' fraction was heterogeneous and contained soluble cell fractions as well as cellular membranes. A possible location for membrane sterol ester and sterol was in lipid droplets in conidia. The spores of several fungi, including Aspergillus species, contain droplets of lipid which are presumed to be triglycerides (Gunasekaran, Hess \& Weber, 1972) and such droplets are present in a strain of $A$. fumigatus (Campbell, 1971). Stone \& Hemming (1968) found sterol and sterol ester in subcellular fractions of $A$. fumigatus mycelium in amounts similar to those observed during the present study. Sterol ester comprised $24.8 \%$ total sterol, and although no data for wall sterol or sterol ester were presented, most of the sterol and sterol ester was present in membrane organelle fractions, rather than the soluble fractions of mycelium. Marriott (I975) observed that sterol ester represented a major component of the neutral lipid in the plasma membrane of Candida albicans.

The radioactive-labelling experiments showed that although the membrane sterol ester was metabolically more active it was unlikely that it was a precursor of wall sterol ester. The lack of increase in specific activity of the wall sterol and sterol ester after the first hour of germination was not due to a cessation of synthesis, since the 'label-chase' and 'pulse-chase' experiments showed that both sterol and sterol ester in the wall remained metabolically labile, suggesting that these components were turning over during germination. It appears that the turnover of wall sterol ester was greater than that of wall sterol, and that these rates declined during germination. The conidial wall in Aspergillus species, including $A$. fumigatus, is a complex structure (Florance, Denison \& Allen, 1972; Martin, Uruburu \& Villanueva, 1973; Campbell, I97I; Ghiorse \& Edwards, 1973), containing several morphologically distinct layers. The turnover of wall sterol and sterol ester may be involved in changes in the conidial wall during germination. 
Triglyceride levels in A. fumigatus 2085 fell rapidly during the early stages of germination (unpublished results). An increase in the endogenous acetate pool would have slowed the flux of external radioactive sodium acetate through this pool. This would have accounted for the high pool radioactivity observed at the start of germination. The reason for the elevated level of radioactivity in the nucleic acid fraction during the first hour of germination has not been determined. Experiments using radioactive precursors demonstrated that there was virtually no de novo DNA synthesis and very little RNA synthesis during the first hour of germination, although there may have been some rapid turnover of certain RNA species triggered by germination. Nucleic acid metabolism differs widely amongst fungal species (Holloman, 1970).

The radioactive-labelling experiments demonstrated that from the start of germination the specific activities [c.p.m. $(\mu \mathrm{g} \text { sterol })^{-1}$ ] for sterol were higher than those for sterol ester. The greater metabolic lability of sterol may indicate that it was metabolized in this form rather than as sterol ester. The possibility that membrane sterol ester could have been derived from small contaminating wall fragments was excluded because the labelling patterns of wall and membrane sterol were different.

Conidia became sensitive to polyenes at the time during germination when membrane sterol metabolism changed dramatically. It was possible to reduce the specific activity of membrane sterol with a non-radioactive acetate 'chase' when conidia were resistant to polyene. During this period there was no increase in the amount of membrane sterol, so this reduction in specific activity presumably represented considerable turnover (20 to $50 \%$ per hour). When conidia were sensitive to polyene the specific activity of membrane sterol could not be reduced with a non-radioactive acetate 'chase'; this was not due to the cessation of membrane sterol synthesis, since sterol could be labelled radioactively at this time. Possibly the turnover of membrane sterol was altered when it became complexed with polyene. However, the fact that polyene sensitivity and sterol metabolism changed at the same stage during germination did not mean necessarily that the two phenomena were causally linked.

The authors wish to thank Professor E. F. Gale and Dr D. B. Archer for their continued interest. This work was supported by a grant from the Medical Research Council.

\section{REFERENCES}

Adams, B. G. \& Parks, L. W. (I968). Isolation from yeast of a metabolically active water-soluble form of ergosterol. Journal of Lipid Research 9, 8-II.

Breivik, O. N. \& OWades, J. L. (1957). A semimicro method for the determination of the percentages of ergosterol and 24,28 dehydroergosterol in yeast fat. Journal of Agricultural and Food Chemistry 5, 360-363.

Campbell, C. K. (1971). Fine structure and physiology of conidial germination in Aspergillus fumigatus. Transactions of the British Mycological Society 57, 393-402.

Florance, E. R., Denison, W. C. \& Allen, T. C., $J_{R}$ (1972). Ultrastructure of dormant and germinating conidia of Aspergillus nidulans. Mycologia 69, I I 5-I 23.

Folch, J., Lees, M. \& Sloane-Stanley, G. H. (1957). A simple method for the isolation and purification of total lipids from animal tissue. Journal of Biological Chemistry 226, 497-509.

Gale, E. F., Johnson, A. M., Kerridge, D. \& KoH, T. Y. (I975). Factors affecting the changes in amphotericin sensitivity of Candida albicans during growth. Journal of General Microbiology 87, 20-36.

Ghiorse, W. C. \& EDWARDS, M. R. (1973). Ultrastructure of Aspergillus fumigatus conidia development and maturation. Protoplasma 76, 49-59.

Goulston, G., Goad, L. J. \& Goodwin, T. W. (1967). Sterol biosynthesis in fungi. Biochemical Journal 102, 15 C-I 7 C.

Gunasekaran, M., Hess, W. M. \& Weber, D. J. (1972). The fatty acid composition of conidia of Aspergillus niger v. Tiegh. Canadian Journal of Microbiology 18, $1575^{-1} 576$.

Hendrix, J. W. (1970). Sterols in growth and reproduction of fungi. Annual Review of Phytopathology 8, I 1 I-I 30.

Holloman, D. W. (I970). RNA synthesis during fungal spore germination. Journal of General Microbiology 62, 75-87.

Kerridge, D. \& Russell, N. J. (1975). Polyenes: actions and prospects. In Chemotherapy Progress, vol. 6, Proceedings of the Sixth International Congress of Chemotherapy, pp. III-116. New York and London: Plenum Publishing Corporation. 
Kitajima, Y., Sekiya, T. \& Nozawa, Y. (1976). Freeze-fracture ultrastructural alterations induced by filipin, nystatin and amphotericin $B$ in the plasma membranes of Epidermatophyton, Saccharomyces and red blood cells. A proposal of models for polyene-ergosterol complex-induced membrane lesions. Biochimica et biophysica acta 455, 452-465.

LAMPEN, J. O. (1966). Interference by polyene antifungal antibiotics (especially nystatin and filipin) with specific membrane functions. Symposia of the Society for General Microbiology r6, 1 I I-1 30.

MARRIOTT, M.S. (I975). Isolation and chemical characterization of plasma membranes from the yeast and mycelial forms of Candida albicans. Journal of General Microbiology 86, I 1 5-1 32.

Martin, J. F., URUburu, F. \& Villanueva, J. R. (1973). Ultrastructural changes in the conidia of Penicillium notatum during germination. Canadian Journal of Microbiology 19, 797-801.

Marty, A. \& Finkelstein, A. (1975). Pores formed in lipid bilayer membranes by nystatin. Differences in its one-sided and two-sided action. Journal of General Physiology 65, 515-526.

Nickerson, W. J. (1963). Molecular bases of form in yeasts. Bacteriological Reviews 27, 305-324.

Nozawa, Y., Kitajima, Y., Sekiya, E. \& ITo, Y. (1974). Ultrastructural alterations induced by amphotericin B in the plasma membrane of Epidermatophyton floccosum as revealed by freezeetch electron microscopy. Biochimica et biophysica acta 367, 32-38.
RuSSELL, N. J. (1975). Lipids in the conidiospore wall of Aspergillus fumigatus. Proceedings of the Society for General Microbiology 2, 90-9I.

Russell, N. J., KerRIDGe, D. \& Gale, E. F. (I975). Polyene sensitivity during germination of conidia of Aspergillus fumigatus. Journal of General Microbiology 87, 35I-358.

Smith, J. D. \& Silverman, P. M. (1973). Lipid turnover during morphogenesis in the water mold Blastocladiella emersonii. Biochemical and Biophysical Research Communications 54, I I9 I-I I97.

Stone, K. J. \& Hemming, F. W. (I968). The characterisation and distribution of hexahydropolyprenol esters in cultures of Aspergillus fumigatus Fresnius. Biochemical Journal rog, 877-882.

Thompson, E. D., KNights, B. A. \& Parks, L. W. (1973). Identification and properties of a sterolbinding polysaccharide isolated from Saccharomyces cerevisiae. Biochimica et biophysica acta 304, I32-I4I.

Weber, D. J. \& Hess, W. M. (1974). Lipid metabolism and ultrastructure during spore germination. In Fungal Lipid Biochemistry, pp. 289-329. New York: Plenum Publishing Corporation.

WeETE, J. D. (editor) (1974). Fungal Lipid Biochemistry. New York: Plenum Publishing Corporation.

WeETE, J. D. \& LASETER, J. L. (I974). Distribution of sterols in the fungi. I. Fungal spores. Lipids 9 , $575-581$. 